\title{
Ovarian Development of House Fly (Musca domestica L.) (Diptera: Muscidae)
}

\author{
Karim M. Ahmed \\ Crop Protection Dep. \\ Bakrajo Technical Institute \\ Sulaimani Polytechnic University \\ Sulaimany, Iraq \\ Karim.ahmed@spu.edu.iq
}

\author{
Havall M. Amin \\ Crop Protection Dep. \\ Bakrajo Technical Institute \\ Sulaimani Polytechnic University \\ Sulaimany, Iraq \\ Havall.Amin@spu.edu.iq
}

\begin{abstract}
The ovarian development of Musca domestica, was examined under light microscope. There are two ovaries in the adult female of fly. Each ovary was formed of about 60-70 polytrophic ovarioles. The ovariole in cross sections organized in several circles. From cytological observations, ovary development and oogenesis could be divided in to 6 stages; ovaries with no noticeable follicle cells existing were characterized as (stage1), the follicle-growing stages considered as (stage 2, 3), the vitellogenen in stages (stages4, 5)and mature egg stage (stage6). The oocyte initiated development at first stages of oogenesis; the nurse cells and follicle epithelial cells were considered to fulfill important functions with regard to the growth of the oocyte.
\end{abstract}

Keywords: Musca domestica, Muscidae, ovarian development, oogenesis.

\section{INTRODUCTION}

Musca domestica is the insect that breeds in a wide diversity of organic substance mainly domestic waste which affects animal husbandry and environment. House flies consider a significant pest associated with transmission of numerous human and animal pathogens $[1,2]$. They caused great amount of diseases like cholera, typhoid, paratyphoid, salmonellosis, polio, coxsackie virus, hepatitis, amoebae dysentery, and bacillus dysentery [3, 4] as well as transmission of shigellosis and other diarrhea disease [5]. The house fly one of the sanitary importance, show rapid development of the ovary after emergence and numerous eggs are laid during the adult stage, studies on the ovarian development of house fly are necessary for comprehension of life cycle and for analysis of the action of chemosterilants [6].

The ovary of insect are organs bilaterally situated and consist of a number of ovarioles categorized as meroistic (teletrophic and polytrophic) or panoistic. The simplest ovary is panoistic type and there are no trophocyte or nurse cells, while the meroistic ovariole contains both types of cells. In panoistic ovary oocyte cells are supplied by the epithelial follicle cells, while in merostic ovary nutrition is supplied by both trophocyte and follicular cells [7, 8]. Panoistic ovary are exist in stoneflies, fleas, apterygotes insects, grasshoppers, stoneflies, crickets, termites, dragonflies and some beetles [8,9], meroistic type are present in butterflies, moth, and flies [10].
Ovaries of insect are consist of tubular parts termed ovarioles. Generally, the developed ovarioles comprise of three distinic regions: (1) the terminal thread, which connects the ovariole to the fat bodies; (2) germarium region, where mitotic divisions of the germ cells occurred in this region; and (3) vitellarium region, employed by lined arrangement of the ovarian parts consist of somatic cell and germ line called ovarian follicles. Adult insect females naturally produce a great amount of eggs to transmission their genesis and to that end they participate significant resources [11].

In the period of oogenesis, carbohydrates, lipids and proteins other substances are commonly accumulated in the development oocyte [12]. Synthesis of yolk proteins is a vital process for the growth of the egg. In this time, quick growth of oocyte arises owing to yolk substance accumulation [13]. Vitellogenesis, is synthesizing a cluster of proteins creating outside the ovary, is the chief constituent of the yolk and deposited as vitellin in oocytes [14]. Insect ovaries are three kinds, meroistic telotrophic, meroistic, telotrophic and panoistic $[15,16]$. In three kinds of ovary follicle epithialial cells enclosed the germ cell and interrelate with it closely throughout oocyte growing. Panoistic ovary is the primitive in morphology, comprising of an oocyte encircled by a follicle epithial cell layer. Other meroistic ovaries have more complex cytological origins and physiologies. Oogonium divides in to produce cystocytes which are group of related cells remain joined by cytoplasmic channels. Single cell of the cystocytes develops to oocyte and rest developed to nurse cells. Trophocytes (nurse cell) straight donate macromolecules substances and cytoplasm to the growing oocyte throughout vitellogenesis. Investigation of reproductive system of insect female is imperative founded on the point that such organs as the ovary goal to precisely yield several progeny in every generation in the somewhat short life time of adult insects. Previous investigation has been showed to examine the ultrastructure insect ovaries in various species (Cochliomyia hominivora)[17]; the snipe fly(Rhagio lineola)[18]; (Tinearia altemata) [19]; dragon fly [20]; Apis mellifera [21] and Haemato pinssuis [22].

In order to fill gap of information of development of this insects, the purpose of this work was hence to examine the ovaries this insect by light microscope. This should give insight in to ovarian morphology and likewise into 
consecutive growth of ovarian. Availability of such facts would be valuable as biological information about Musca domestica which might be useful toward fly control labors and applications of the field forensic entomology.

\section{METHODS AND MATERIALS}

\subsection{Fly rearing}

Adult flies were collected from local area using a sweep net and reared in laboratory at $25 \pm 2 \mathrm{C}^{\circ} \mathrm{RH} 40-50 \%$, photoperiod 12:12 L: D [23]. Flies kept in typical boxes of $40 \mathrm{~cm} \times 30 \mathrm{~cm} \times 30 \mathrm{~cm}$. The frame of the boxes with 25 meshes and the base was of hard board. The front side with long sheath cloth for purpose of feeding and cleaning [24]. Adult flies were supplied with food consisting of sugar solution $10 \%$ and powdered milk. Milk and wheat flour mixture was prepared at the weight proportion 3:1 and 50gm of this mixture were placed in small pot as an oviposition site [25].

\subsection{Light Microscope Analysis}

To evaluate the alterations in growing of the insect ovaries by light microscope (Motic, China), adult females raised from the same group were forgone by transporting them from boxes through a tube into a refrigerator at $4 \mathrm{C}^{\circ}$ and left for 10min [26]. Females isolated from male adults of house flies by pressing gently on the abdomen of fresh killed fly which cause the ovipositor extended and determined the sex of fly [27]. This process repetitive everyday commencement with anew arisen female adult flies (12 hours old) till the females become 5days old. Following the forgone adult female flies fixed for $24 \mathrm{~h}$. in Carnoys fluid [28]. Flies fixed in graded ethanolic concentrations $(10 \%, 30 \%, 50 \%, 70 \%, 80 \%, 90 \%, 95 \%$ and $100 \%$ ) which are prepared by dilution from absolute ethanolic solution to attained dehydration. Then the flies were placed into xylene to attain clearness and fixed in paraffin [29]. Flies were successively sectioned at thickness of $5 \mu \mathrm{m}$ and then sections of tissues stained with Eosin and Haematoxylin to reveal overall histological alterations. All sections were exanimate by compound microscope (Motic, China) and photographed using amounted camera (AmScope 500China).

\subsection{Stages of Ovarian Development}

As the oogenesis is synchronous in house fly, the sorting of ovarian growth was founded on the situation of the greatest progressive follicles when conveying individuals to a specific stages of oogenesis [30,31]. Ovaries with no noticeable follicle cells existing were considered stage1 and stage 2 initiated when the development oocyte totally encircled with epithelial follicle cells. The trophocytes situated at the frontal end of the follicle, while oocyte situated at the posterior end (stage3). The terminal oocyte enlarged in size quickly throughout the vitellogenesis period, and yolk protein substance deposited in to growing oocyte (stage4). At the end of the vitellogenesis once the secretion of chorion was finished, trophocytes (nurse cells) and epithelial follicle cells disintegrated (stage5).
The mature oocyte is enveloped in the chorion. Oocyte in this period attained full grown of normal egg shape, as the process of ovulation continuous, mature egg expelled from ovaries, while vacant follicle remnants contracted and distorted creating sphere-shaped body recognized as corpus luteum, and the existing of follicle remnants in ovary is the indication of (stage 6).

\section{RESULTS}

A pair of ovaries was observed on house fly (Musca domestica L.), each one with (60-70) ovarioles. The ovaries are white in color; abundantly provided with the trachea and located ventral-dorsally in abdomen cavity on both side of hind gut. Posteriorly all ovarioles releases in to the lateral oviduct. Medially the lateral oviducts unite medially to make the common oviduct. Each ovaries of mature female house fly consist of about 60-70 ovarioles which are organized in 4-5 circles (Fig.1a). The dorsal ventral directions of the follicle point to arranged in different directions (Fig.1b). Immediately after emergence the ovarioles is white in color, glowing and minor forms of about $(0.25 \mathrm{~mm})$ in length. The ovariole gradually increases in size and the egg in the ordinary situation takings four days to developed and become mature and the egg laying normally begins five days after of emergence of flies. Growth of follicle could be divided in to 6 stages from the cytological and morphological features in relation to the period after emergence. These stages were the follicle-differentiating stages (stage1), the follicle growing stages (stage 2,3 ) the vitellogenic stages (stage 4,5$)$ and the mature egg stage: Stage(6).

Stage1: No noticeable follicle cells existing in ovary were considered as stage1 (Fig.1c).

Stage2: The primary follicle differentiated from the germarium, which was almost spherical in shape and small in size which distinguish in to single minor oocyte and enlarged in size and the oocyte was completely encircled with follicle epithelial cells (Fig.1d).

Stage3: The follicle has become ellipsoidal and the oocyte hypertrophic, the size of follicle enlarged.

The oocyte initiated to increase in size inhabiting about one third of the egg follicle and become entirely disconnected from the residual of nurse cells, meanwhile the nurse cells occupied the remnant two thirds (Fig.1e). 


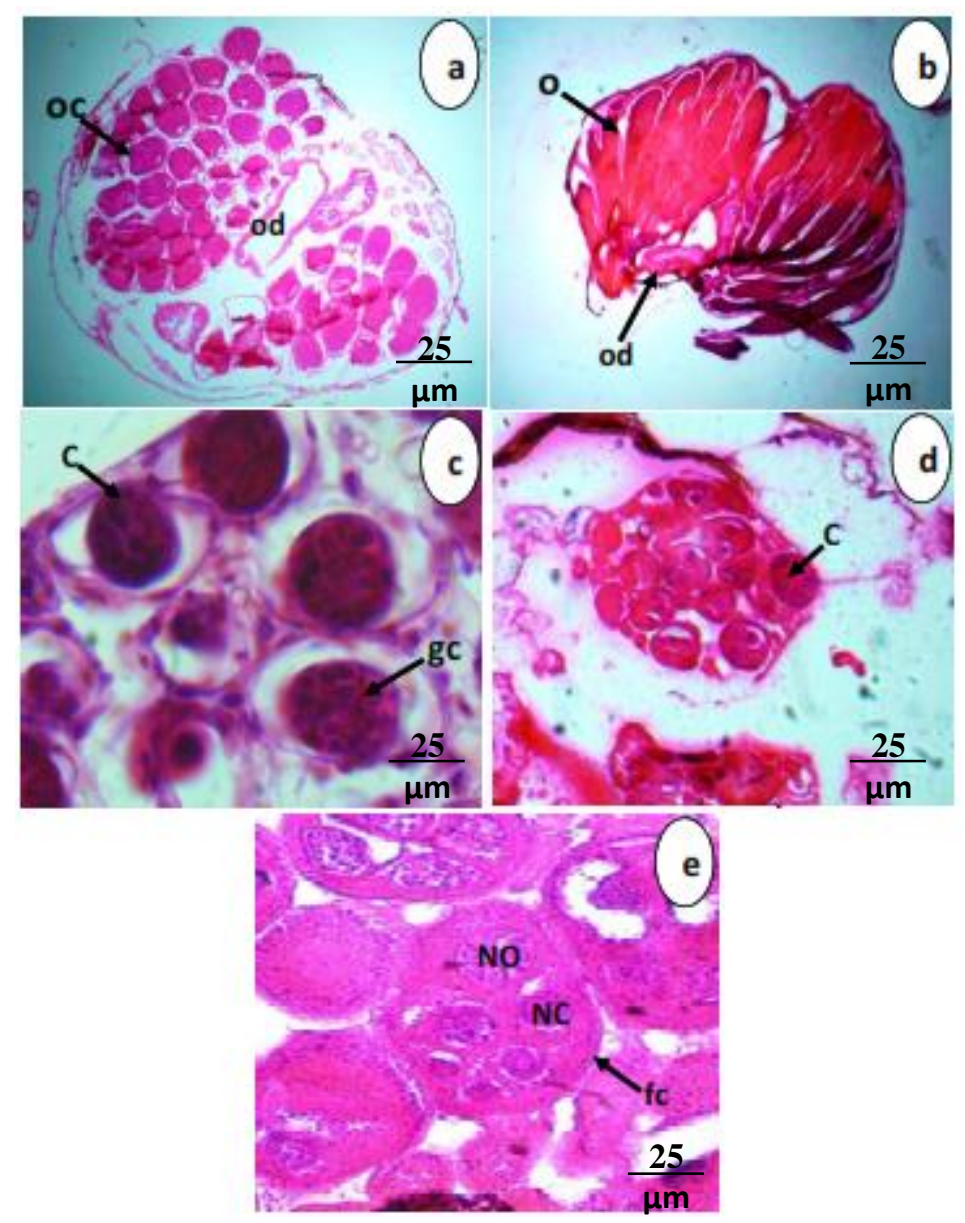

Figure 1: Maturation stages of house fly ovary

(a) C.S. ovary of the adult female of housefly $(4 x)$.

(b) L.S. ovary of the adult female of house fly (4x).

(c) Stage 1 : C.S. of germanium (germ region) of the ovary of female house fly (100x).

(d) C.S. first follicle (10x).

(e) C.S. of the second stage of follicle (10x), Third stage of oocyte, nurse cells situated at frontal end of the oocyte (40x).

\section{C.S.: Cross Section; $\quad$ L.S.: Longitudinal Section; $\quad$ OC: Oocyte; O: Ovariole; fc: Follicular cell; od: Ovary duct; C: Cystocyte; gc: Germ cell; NO: Oocyte Nucleus; NC: Nurse Cell Nucleus}

Stage4: The follicle has become elongated and oocyte has initiated the development. Follicular epithelial cells are columnar; those around the nurse cells extremely thin. The basal oocyte increases in size and becomes elongated at the beginning of vitellogenesis (Fig.2a). The epithelial cells become columnar, resulting in intracellular spaces in the follicular epithelium and separate from the ooplasm forming spaces all along the epithelial lining oocyte (Fig.2b). In this stage also the nurse cells have attained their maximum sizes with development circular nuclei have been enlarged, from anterior part to the boundary of the oocyte, and initiation of vitellogenesis in the oocyte (Fig.2c).

Stage5: The oocyte has reached its maximum size (Fig.2d); the nucleus of oocyte situated at the frontal part of oocyte and just beneath the vitelline membrane. As the consequence of the elongation of the oocyte, the epithelial follicle cells were became lengthened due to the expanding surface of the oocyte, the nurse cells have degenerated in the anterior portion of the oocyte (Fig.2, e). Protein, lipid, and glycogen are deposited abundantly in the ooplasm, forming yolk spheres. DNA has been concentrated in the degenerated nurse cells (Fig.2f). Follicular epithelium that finally becomes thinner and secreted chorine over the oocyte. 


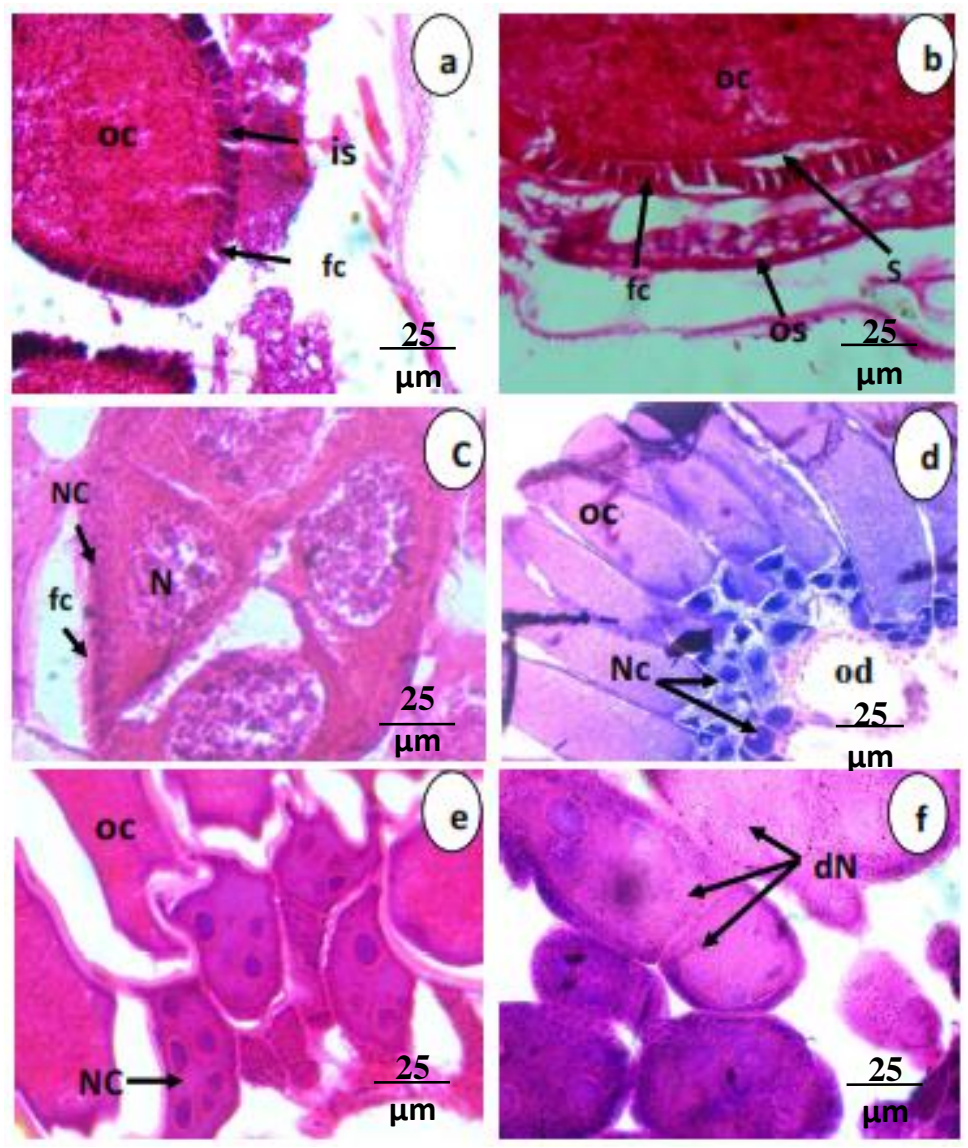

Figure 2: Maturation stages of house fly ovary
(a) C.S. of oocyte that become elongated, stage 4 (40 x).
(b) C.S. of oocyte the epithelial cells become columnar, (100x).
(c) C.S. of the oocyte with big nurse cell nuclei (100x).
(d) Stage5. L.S. of the follicle, cells have degenerated (10x).
(e) L.S. of the oocyte, the nurse cell degenerated (40x).
(f) L.S. of nurse cell (100x).
C.S.: Cross Section;
L.S.: Longitudinal Section;
OC: Oocyte; is: inter cellular space;
fc: follicular cell; OS: Ovariole Sheath; s: space between the oocyte and follicular cell; NC: Nurse cell ; od: ovary duct; dN: Degenative Nurse cell; $\quad$ N: Nucleus of nurse cell.

Stage 6: The mature oocyte is enveloped in the chorion (Fig.3a). Oocyte attained full size and shape and resemble the typical mature egg (Fig.3b). The follicle increased in size. Due to the disappearance and degeneration of nurses cells, oocyte only remain and occupied the follicle. The mature oocyte consists of three main parts: the chorion, the vitelline membrane, and yolk mass. The yolk bulk substance employed the entire inside the vitelline membrane (Fig.3c). Two types of granular yolk spheres exist as big spheres and minor spheres. The epithelial follicle cells extinct after the construction of the vitelline membrane and complete deposition of the yolk. The excretion and deposition of the chorion followed, and it was consisted of the internal thin homogenous layer, the endo chorion (ENC), which appeared to be consisted of granular filament layer, and the exochoiron (EXC), which was thicker than the endo chorion (Fig.3d). The follicular cell between the nurse cell and oocyte has disappeared.

\section{DISCUSSION}

The study focused on the biological reproduction of insect pests concerning sexual development is of greatest importance if flies are successful to be controlled. This is particularly factual for those species able to creating great numbers of progenies by females. In this respect, the present study was dedicated to studying the development and morphology ovary of the female reproductive ovaries of house fly (Musca domestica L.) using light microscope. Musca domestica comparable to other insects has polytrophic ovaries in which the ovary contains large number mature eggs which are ready for fertilization for production of progeny. In deterring the development stages ovarian in flies, little variation arises among the several researches upon evaluation of the number stages of ovarian and variable description that have been stated [26]. The present work revealed 


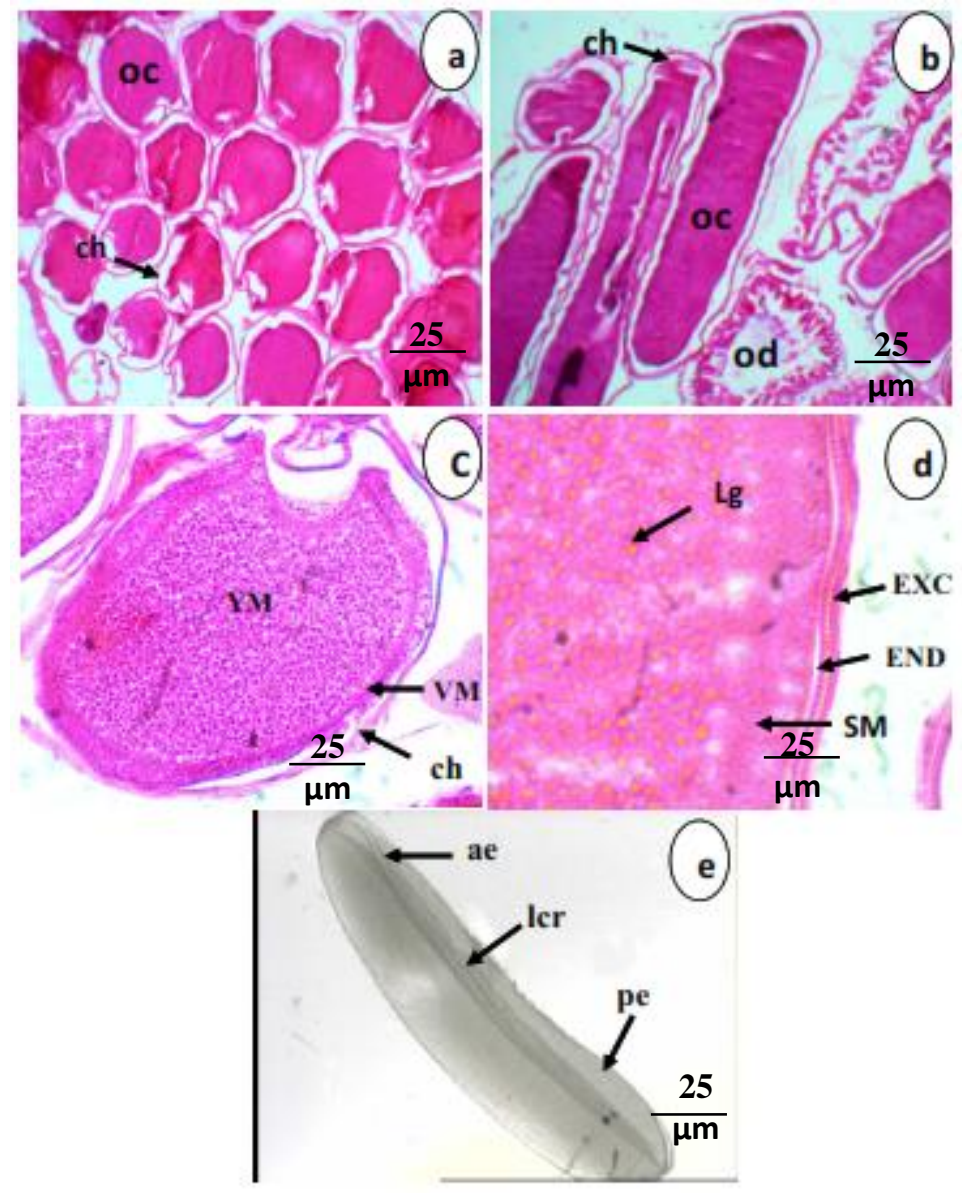

Figure 3: Maturation stages of house fly ovary

(a) C.S. of the oocyte, the mature oocyte is enveloped in the chorion. (10x).

(b) L.S. of the oocyte, the follicle reached of typical egg shape (10x).

(c) C.S. of the oocyte (40x).

(d) C.S. of chorion mature egg (100x).

(e) Mature egg $(4 \mathrm{x})$.

\section{C.S: Cross Section; $\quad$ L.S.:Longitudinal Section; $\quad$ OC: Oocyte; Material; VM: Vitelline Membrane; Lg: Large granule; END: Endochoiron; ae: anterior end; pe: posterior end; od: Ovary duct; $\quad$ ch: Chorion; YM: Yolk
SM: Small Granule; EXC: Exochoiron;
lcr: longitudinal curved ridge.}

that from cytological observation of oogenesis in female house fly ovary could be divided in to 6 stages; ovaries without noticeable follicles characterized as (stage1), the follicle growing stages (stage2,3) the vitellogenic stages (stages4,5) and the mature egg stage(stage6). This finding corroborates with [32] which reported that the ovarian development and oogenesis in Musca domestica path through progressive (6) stages in the ovary, and also corroborates with $[33,34,35]$ who stated that the oogenesis was subdivided in to 6 stages in Musca domestica. In cross sections the ovarioles of house fly are organized in 4-5 circles. This in agreement with [32] which reported in cross sections, the ovarioles of female of house fly is organized in 4-5 circles. The first period of oogenesis was signed by appearance a new follicle and leaving the germarium region, the follicular epithelial cells were organized around anew formed follicle and the follicle was incompletely disconnected from germarium region and the oocyte was not enclosed by epithelial cells. Related notes were stated by [36, 37] for $A$. aegypti, $C$. pipiens quinquefasciaatus, and A. gambiae and by [38] Culex pipiens quinquefasciaatus.

In the normal course of development of considerable changes have been observed in the epithelial follicle cells of the ovary of Musca domestica. This in agreement with $[39,40]$ have also observed the appearance of clear spaces between the apical regions of the follicular cells in Melanopus sanguinipes( Orthoptera, Acrididae) and dragon fly Pantala flensavesc(Anisoptera, Libellulidae). In house fly, the basal oocyte increases in size and become spherical at the beginning of vitellogenesis. The epithelial cell becomes columnar, resulting in intra cellular separate from the ooplasm forming spaces at the time of vitellogenesis. This finding corroborates with [41]. The presence of yolk granules at the apex of follicular cells in present evidence for the intracellular pathway for protein accumulation inside the oocyte. Investigators like [42, 43] have also reported that the proteins from the hemolymph are transported through the intracellular spaces of the epithelium in to the developing oocytes during 
vitellogenesis of the insects. It is opined that the enlargement of the inter follicular channels is one of the vitellogenic events in the follicular cells at the one set of vitellogenesis. According to [44] the potency of the inter follicular channels is directly correlated with increasing in the vitellogenin uptake. Follicular epithelial cells cover the development oocyte, throughout yolk synthesis, the epithelial cells of separate follicles proceeded from columnar shape to cuboid shape to squamous and the epithelial follicle cells lengthened owing to the development of the oocyte, the gathering of yolk substance in oocyte, which in its continuing enlargement drives the nurse cells up to the frontal end of the follicle. In future stages, the follicle develops slower and packed with yolk granules which become considerably bigger and opaque. These observations were consistent with those [45] and with [38] for Culex pipiens quinquefasciaatus. [46] Indicated that the epithelial follicicle cells of Mansonia species in young follicle are cuboidal in shape, when the follicle lengthened, the epithelial cells increasingly shrinks in thickness. At last stages of development, the epithelial cells were very thin. Based on [47], through out of the development mosquito ovary stages, the epithelium cells became gradually thinner and is lastly reduced in to clusters collapsed cells hard to be noticed. This also determined in the oocyte of Melanogrylus desertus, columnar epithelium cells in previtellogenic oocyte slowly altered from cuboidal shape to squamous shape when yolk synthesis proceed [48].

The processes of vitellogenesis stage was signed by the presence of nurse cell at the frontal end of the growing oocyte, and continued until the whole growth egg shell (chorion). A great quantity of yolk protein substance was accumulated in to the growing oocyte throughout this stage, which produced a quick alteration in the ovarian organization, and the nucleus of oocyte became less visible, meanwhile it was closely enclosed by yolk substance. Types of the terminal follicle, in combination with the index of ovarian, provided precise determination for the stages of oogenesis and were reliable with the finding of [49].

The house fly oocyte terminate the development after the nurse cell had disintegrated after the yolk protein synthesis was ended, and the development of creating chorion (egg shell) initiated, this phenomenon would indicate that the function of the nurse cells was strictly related to oocyte development, when the growth of oocyte complete, the outcome of nurse cells were remain outside of the chorion, after egg laying the relics of the nurse cells were seen in the ovary these observations were consistent with [37] for Culex pipiens quinquefasciaatus.

\section{CONCLUSION}

Histological observation of ovarian development of house fly revealed that the evidence from present work not only funds the earlier finding of the quick ovarian growing of this insect, but also ability to create various progeny or eggs in every generation. Evidence from present work pertaining to the ability of quick ovarian maturation, great production of progeny, and moderately long lifetime of this insect are of special anxiety if fly control plans are being considered. Particularly essential in regions with ambient temperature like tropical subtropical and in regions that Musca domestica could be associated in the medical transmission of pathogens.

\section{REFERENCE}

[1] A.Malik, N.Singh, S.Satya, "House fly (Musca domestica): a review of control strategies for a challenging pest," Journal of Environmental Science and Health, B.42:453-469, 2007.

[2] S.M.Palacios, A.Bertoni, Y.Rossi, R.Santander, A.Urizua, Insecticidal activity of essential oils from native medical plants of central Argentina against the house fly, Musca domestica L., Parasitology Research,106:207:750, 2009.

[3] T.K.Graczyk, R.Knight, R.H. Gilman, M.R.Cranfield, "The role of non-biting flies in the epidemiology of human infectious diseases," Microbes and Infection, 3:231-235, 2001.

[4] O .C.Ugbogu, N.C. Nwachhukwu, U.N. Obguagu, "Isolation of from houseflies in Uturu, Nigeria," Africian Journal of Biotechnology, 5:1090-1091, 2006.

[5] World Health Organization, Enviromental Health in Emergencies and Diaters. Apractical guide, Genva, Switterland, 2002.

[6] H.Sakuri,"Studies on the ovarian development in house fly, Musaca domestica Vicina Macquart," Japan, J. Med. Sci. Biol., 26,239-248, 1973.

[7] M.Mazzini, "An overview of egg structure in orthopteriod insects," In: Bacccetti BM, editor. Evolutionary Biology of orthopteroid Insects, Vol.11.Chichester, UK: Ellis Horwoodltd, pp.358-372, 1987.

[8] R.Singh, Elements of Entomology, Part2. Morphology,Physiology and Development, Chapter 10, Reproductive System, Meerut, India: Rastogi Publications, pp.153-164, 2007.

[9] P.F.Bonhag, "Ovarian structure and vitellogenesis in insects," Ann. Rev. Entomol., 3: 137:160, 1985.

[10] J.T.Bradley, M. Kloc, K.G Wolfe, B.H. Estridge, S.M.Bilinsk, "Balbiani bodies in cricket oocyte s: development, ultrastructure, and presence of localized RNAs Differentiation," 67:117-127, 2001.

[11] L.Swevers, AS Raikkhel, TW Sappington, P. Shirk, K.Iatrou, "Vitellogenesis and post-vitellogenic maturation of insect, follicle.In: LI.Gilbert, K. Iaotrou, SS. Gill, "editors Comprehensive Molecular Insect Science," Oxford, UK: Elsevier, pp87-155, 2005.

[12] L.L.Fruttero, S.Frede, ER. Rubiolo, LE. Caavoso, "The storage of nutritional resources during vitellogenesis Panstrongylus megistus (Hemiptera: Reduviidae): the pathways of lipophorin in lipid delivery to development oocytes," J. Insec Physiol, 57:475482, 2011.21

[13] D.Valle, "Vitellogenesis in insect and other groups-a review," Mem Inst Oswaldo Cruz, 88:1-26, 1993.

[14] H.H.Hagedorn, JG. Kunkel, "Vitellogenin and vitellin in insects," Ann Rev Ent., 24: 475-505, 1979.

[15] A.P.Mahowald, Oogenesis.In: Developmental System; Insects, Vol 1, Counce, S J; Waddington, CH,eds, Academic press;London.,UK 1972; pp.1-47. Ho. Gutzeit, K. Sander "Establishment of Polarity in the insect egg (review)," Biology of fertilization, 1:346-377, 1985

[16] H.O. Gutzeit, K. Sander "Establishment of Polarity in the insect egg (review)," Biology of fertilization, 1:346-377, 1985.

[17] T.S.Adams, J.P.Reinnecke, "The reproductive physiology of the screwworm, Cochliomyia hominivorax (Diptera: Calliphoridae)," J. Med. Entomol., 15, 472-483, 1979.

[18] J.Kubrakiewicz, A.Jablonska, M.Mazurkiewicz, S.M.Bilinski, "Differentiation and diversification of the follicular cells in flies: insight from the studies of the lower brachycerans ovaries," Genesis, 36:214-224, 2003.

[19] M.Mazurkiewicz, J.Kubrakiewicz, "Follicular cell differentiation in polytrophic ovaries of a moth midge, Tinearia alternate," Int. J. Dev. Biol., 52, 267-278, 2008.

[20] E.Gainoa, S. Piersanti, M. Rebora, "Egg envelope synthesis and chorion modification after oviposition in the dragonfly Libellula depressa (Odonata, Libellulidae)," Tissue and Cell, 40, 317-324, 2008.

[21] C.A.Neves, L.Gitirana, B.Serrao, "Ultrastructure of the midgut endocrine cells in Melipona quadrifasciata anthidioides (Hymenoptera, Apidae)," [J.E] Bra. J. Biol., 63: 683-690, 2003. 
[22] M.Zelazowska, "Structure of the ovary and the differentiation of follicular epithelium in the pig louse, Haematopinus suis (Insecta: Phthiraptera)," Folia Biol. (Krakow), 53:51-60, 2005.

[23] M.M. Akiner, S.S.Caglar, "The status and seasonal ch anges of organophosphate and pyrethroid resisstance in Turkish populations of the house fly, Musca domestica L., (Diptera: Muscidae)".Journal of Vector Ecology, 31(1):58-64.2005.

[24] K.M. Farahanullah, A.S.Muzaffer, "Toxicity of crude neem leaf extract against house fly Musca domestica L., adults as copared with DDVP ,Dichlorvos,” Turk. J. Zool., 24(4): 219-223, 2000.

[25] T.Kence, T.Jdeidi, "Effect of Malathion on larval competition in house fly (Diptera: Muscidae) populations," J. Econo. Entomo., 90 (1): 59-65, 1997.

[26] T.Chaiwong, K.Sukontason, U.Chaisr, B. Kuntalue, C.Vogtsberger, K.I.Sukontason, "Ovarian ultrastructure and development of the blow fly, Chrysomya megacephala (Diptera: Calliphoridae), "International journal of parasitology Research,4(1):65-70,2012.

[27] S.W.Luther, The house fly, its natural history, medical importance and control, Comstock Publishing Company, Ithaca, New York, pp. 36-38, 1951.

[28] M.S.Patil, K.R. Pawar, C.S. Jawales, "Study of pesticide induced puffs in Chironomus striatipennis,"DAMA International.,1(2):35-38, 2012.

[29] C.Ozlem, "Oocyte development in Melano gryllus desertus (pallas, 1771) (Orthoptera: Gryllidae),” Turk J. Zool., 41:203208, 2017.

[30] B.S.Fletcher, S.Pappas, E.Kapatos, "Changes in the ovaries of olive flies (Dacusoleae (Gmelin) during the summer, and their relationship to temperature, humidity and fruit availability," Ecological Entomology, 3:99-107, 1978.

[31] M.J.Klowden, "Female reproductive system," In:Klowenm MJ, editor. Physiology System in insects, Elsevier, pp187-223, 2007.

[32] K.S.Herman, E.Wolf, Symmetrical Pattern of follicle arrangement in the ovary of Musca domestica (Insecta, Diptera), Zoomorphology, 1981.

[33] K.H.Bier,"Synthese, interzellularer transport und Abbau von Ribnucleinsaureim Ovar der Stubenfliege Musca domestica," J. Cell Biol., 16: +

[34] W.Engels, H.Bierk, "Zur Glykogen espeicherung wahrend der Oogenese und inhervorzeitigen Auslosungdurch Blockierung der RNS-Versorgung (Untersuchungen and Musca domestica)," Wilhelm Roux Arch., Entwicklungsmech Org, 158:64-88, 1967.

[35] H.H.Trepte, "Rate of follicle growth, duration of oogenesis stages and inter individual synchrony of egg development in the $1^{\text {st }}, 2^{\text {nd }}$ and $3^{\text {rd }}$ egg cycle of the house fly, Musca domestica," Zoo1. Jarb. Abt. Anat. Ontog. Tiere, 105:362-370, 1981.

[36] T.S.Detinova, "Age-grouping methods in Diptera of medical importance with special references to some vectors of malaria," MonogrSer Word Health Organ, 47:13-191, 1978.

[37] A.N.Clements, M.R.Boocock,Ovarian development in mosquitoes: stages of growth and arrest and follicular resorption, Shell Research Limited, Sitting bourne Research Center, Sitting bourne, Kent, pp18, 1984.

[38] F.K. Adham, H. Mehlhorn, ZM. EL-Basheir, A.S.Yamany, "Light and electron microscopian studies on the development of the ovaries of Culex pipiens quinquefasciatus(Say)(Diptera:Culicidae)," Parasitol Res.,105:939-948, 2009.

[39] R.H. Elliott, C.Gillot, "Histological changes in the ovary in relation to yolk deposition, allatectomy and destruction of the medium neurosecretory cells in Melanophuss sanguinipes, J. Zool., 54: 185-192, 1976.

[40] A.Parithabhanu, K.J.Kussnumabegam, M.Deepak, "The role of follicular cells during vitellogenesis of oocyte in the Dragon fly Pantala flavescense (Fabricius) (Libellulidae:Anisoptera), International Journal of pure, pp: 334-336, 2013.

[41] T.Zhao, O.S.Graham, S.T.Raposo, "growing of microtubules push the oocyte nuleus to polarize the Drosophila dorsal and ventral axis," Sci., 336 (6084): 999-1003.2012.

[42] B. Stay, "protein uptake in the Cecropia moth," J.Cell. Biol., 28:49-62, 1965.

[43] S.Patchin, K.G.Davey, "The histology of vitellogenesis in Rhodnius prolixus,”J. Insect Physiol., 14:1815-1820, 1968.
[44] P.L. Oliveria, C.G.Katia, M. G. Damiao, M. Hatisaburo, "Uptake of yolk proteins in Rhodnius prolexus," J. Insect Physiol,32: 859-866,1986.

[45] A.J. Nicholson, "The development of the ovary and ovarian egg of a mosquito, Anopheles maculipennis," Meig, $Q \mathrm{~J}$ Micosc .Sci. 65:395-448, 1921.

[46] W.A.Samarawickrema, "Changes in the ovarariole of Mansonia (Mansonioides) mosquitoes in relation to age determination," Ann. Trop. Med. Parasitol., 56:110-126, 1962.

[47] D.S.Bertram, "The ovary and ovarioles of mosquitoes. MonogrSer World Health," 47: 195-210, 1962.

[48] C.Ozlem, "Oocyte development in Melano gryllus desertus (pallas, 1771) (Orthoptera: Gryllidae)," Turk J. Zool., 41:203208, 2017.

[49] P.E.Kendra, W.S.Montgomery, N.D.Epsky, R.R.Heath, "Assessment of female reproductive status in Anastrepha suspense (Diptera: Tephritidae)," Florida Entomologist, 89: 144151, 2006 D.Valle, "Vitellogenesis in insect and other groups-a review,” Mem. Inst. Oswaldo Cruz, 88:1-26, 1993. 